
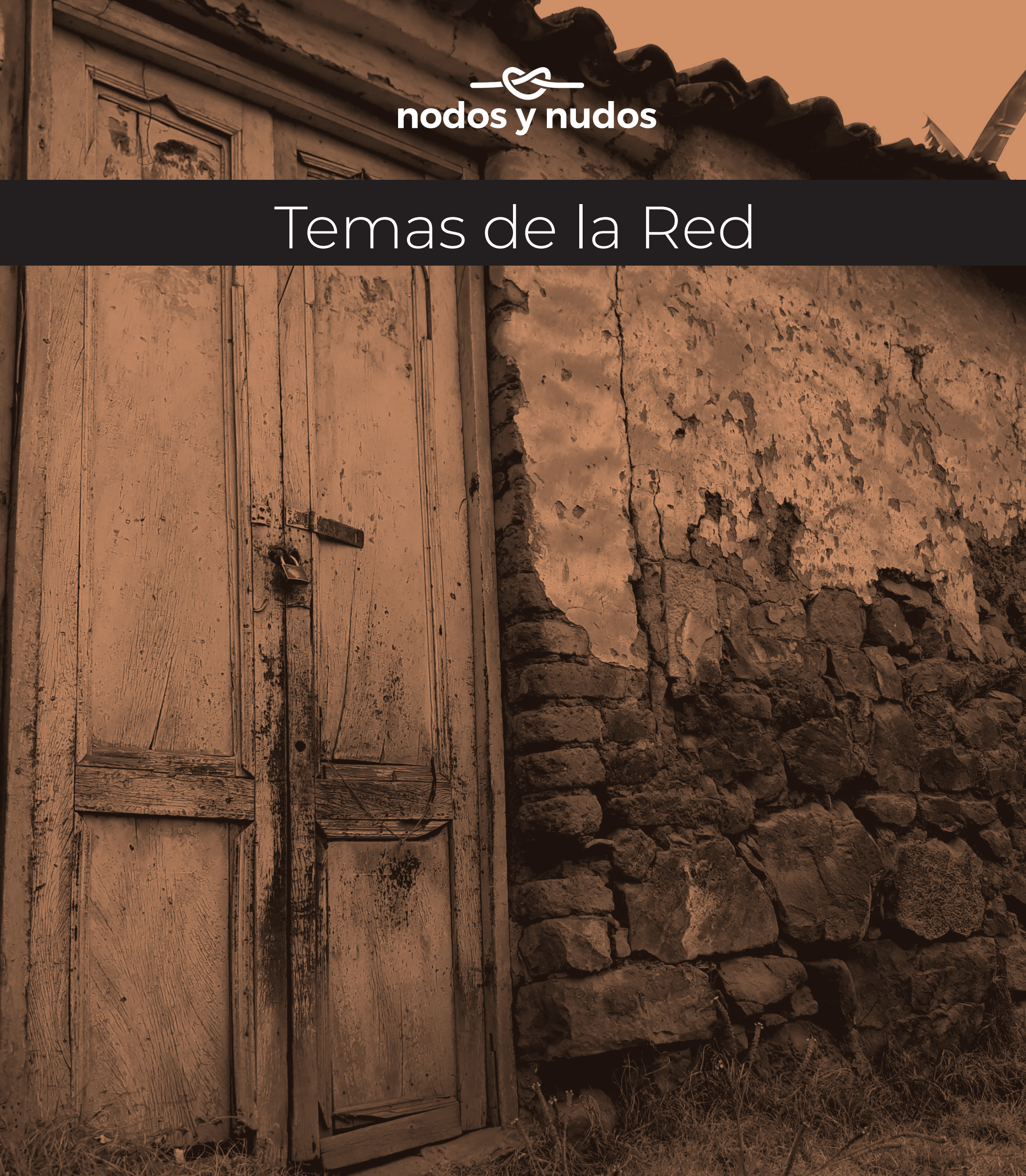

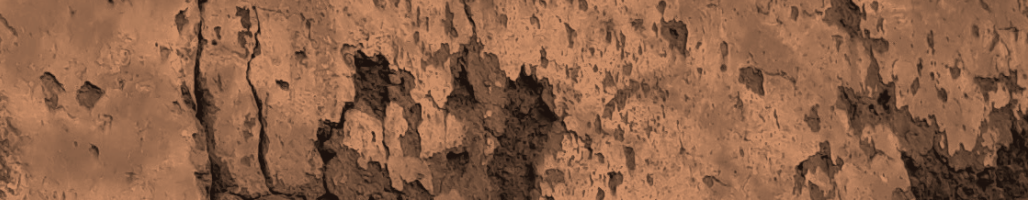
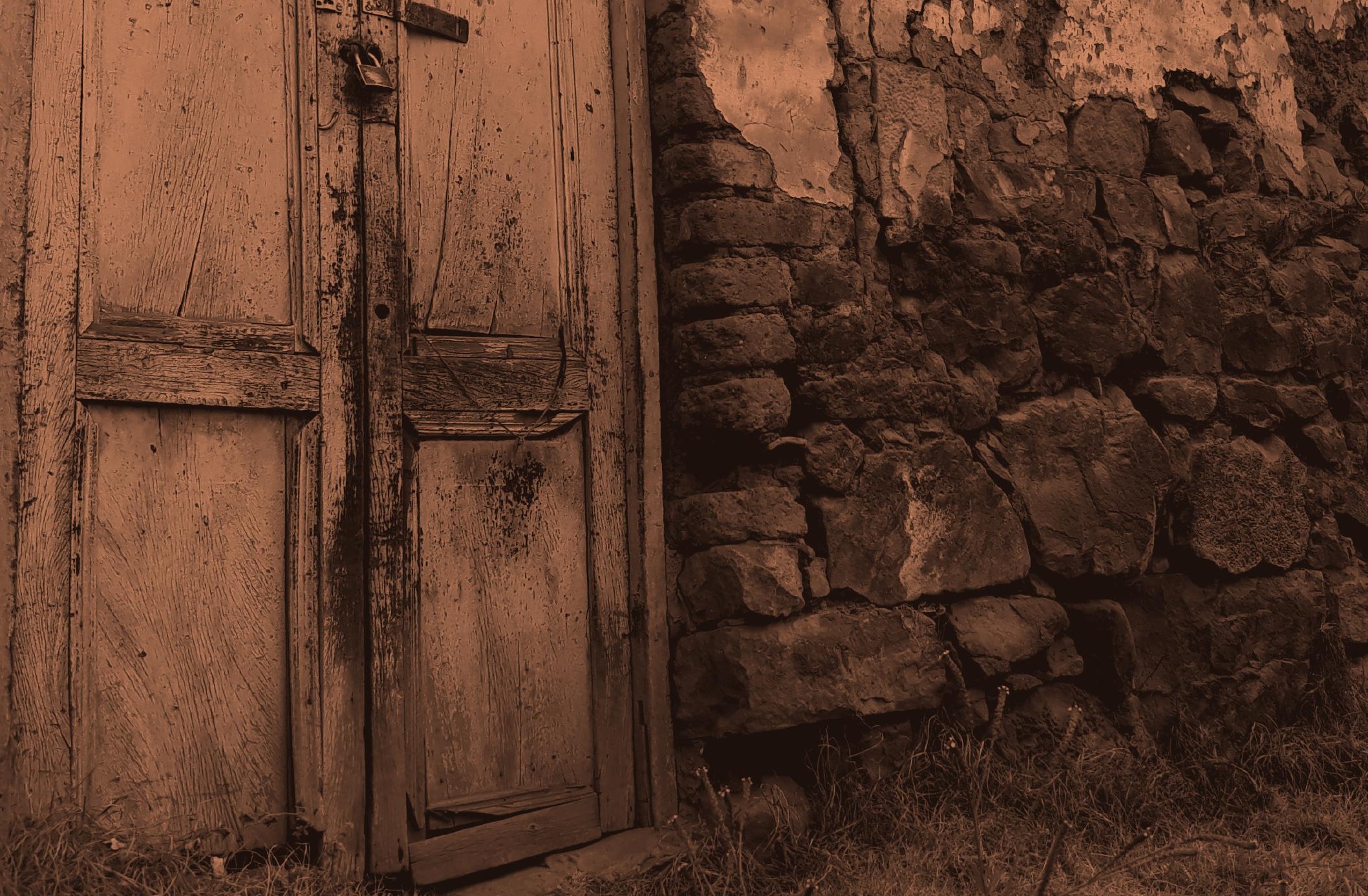


\title{
Infraestrutura das escolas rurais de Educação Básica: desigualdades em relação ao meio urbano*
}

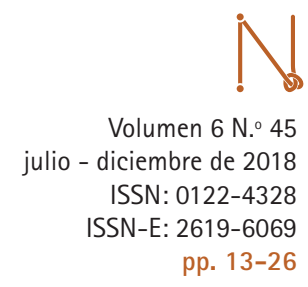

Infrastructure
of Primary Rural
Schools: Inequalities
against Urban Areas

Infraestructura de

las escuelas rurales

de Educación Básica:

desigualdades

en relación con el

medio urbano

\begin{abstract}
Michael Daian Pacheco Ramos"* Edmilson Antonio Pereira Junior" Dalila Andrade Oliveira****
\end{abstract}

Fecha de recepción: 13-02-19

Fecha de aprobación: 19-03-19

\section{PARA CITAR ESTE ARTÍCULO}

Pacheco Ramos, M. D., Pereira, E. y Oliveira, D. (2018). Infraestrutura das escolas rurais de Educação Básica: desigualdades em relação ao meio urbano. Nodosy nudos, 6(45), 13-26. doi:

10.17227/nyn.vol6.num45-9617
* Este artigo é resultado de estudo realizado no âmbito da pesquisa: Políticas públicas para a melhoria do ensino médio: socialização científica, tradução e transferência de resultados. (CNPq 22/2016).

* Professor Auxiliar no Departamento de Ciências Humanas da Universidade do Estado da Bahia - Campus IV, Jacobina. michaeluneb@gmail.com

*** Bolsista de pós-doutorado na Faculdade de Educação da Universidade Federal de Minas Gerais. edmilsonpj@yahoo.com.br

*** Professora Titular de Políticas Públicas de Educação na Faculdade de Educação da Universidade Federal de Minas Gerais. Pesquisadora do Conselho Nacional de Desenvolvimento Científico e Tecnológico (CNPq). dalilaufmg@yahoo.com.br 


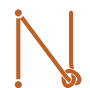

Volumen $6 \mathrm{~N} .{ }^{\circ} 45$

julio - diciembre de 2018

ISSN: 0122-4328

ISSN-E: 2619-6069

pp. 13-26

\section{RESUMO}

Este texto analisa a configuração da infraestrutura das unidades educacionais localizadas em contextos rurais, comparando as escolas urbanas. Utilizamos os dados do Censo Escolar da Educação Básica que permitiu verificar a existência ou não de desigualdades entre as características desses dois tipos de escolas. Os resultados apontam a existência de diferença estrutural significativa entre as escolas rurais e urbanas, cuja precariedade dos aspectos de infraestrutura das escolas relaciona-se diretamente ao processo de valorização dos profissionais da educação. Nas localidades rurais, foram identificadas escolas que não possuiam salas de direção e de professores, secretaria, laboratórios, biblioteca, refeitórios, banheiros e cozinha.

Palavras-chave: Educação Básica; infraestrutura das escolas; meio rural

\section{ABSTRACT}

The article analyzes aspects of the infrastructure of schools located in rural areas, comparing them to urban establishments. Census data were used for Basic Education in the country, which allowed to verify the existence or not of inequalities between the characteristics of these two types of schools. The results showed the existence of an abyssal structural difference between urban and rural schools, whose precariousness of the infrastructure aspects of the schools is directly related to the process of valuation of education professionals. In rural areas, schools were identified that did not have management and teachers' rooms, secretaries, laboratories, libraries, bathrooms and kitchen.

Keywords: Basic Education; school infrastructure; rural area

\section{RESUMEN}

Este texto analiza la configuración de la infraestructura de las unidades educativas localizadas en contextos rurales, comparadas con las escuelas urbanas. Utilizamos los datos del Censo Escolar de la Educación Básica que permitió verificar la existencia o no de desigualdades entre las características de estos dos tipos de escuelas. Los resultados señalan la existencia de una diferencia estructural significativa entre las escuelas rurales y urbanas, cuya precariedad de los aspectos de infraestructura de las escuelas se relaciona directamente con el proceso de valorización de los profesionales de la educación. En las localidades rurales, se identificaron escuelas que no poseían salas de dirección y de profesores, secretaría, laboratorios, biblioteca, comedores, baños y cocina.

Palabras clave: Educación Básica; infraestructura de las escuelas; medio rural 


\section{Introdução}

Este artigo analisa aspectos da infraestrutura das escolas localizadas em áreas ruraise os compara aos dos estabelecimentos urbanos. Foram utilizados dados censitários da Educação Básica no país, o que permitiu verificar a existência ou não de desigualdades entre as características desses dois tipos de escolas.

0 acesso à escola é garantia do direito à educação, regulamentado na Constituição Federal do Brasil (Brasil,1988), na Lei de Diretrizes e Bases da Educação Nacional (LDBen) (Brasil, 1996), no Plano Nacional de Educação (PNE) (Brasil, 2014a), entre outros dispositivos legais. 0 PNE refere às escolas rurais ao estabelecer metas e estratégias relacionadas às populações e escolas do campo, vinculadas à Educação Infantil (Meta 1),ao Ensino Fundamental (Meta 2), ao Ensino Médio (Meta 3), à Educação Especial (Meta 4), à alfabetização (Meta 5), à Educação Integral (Meta 6), à qualidade da educação (Meta 7); à escolaridade média (Meta 8), à Educação de Jovens e Adultos (Meta 10), à Educação Profissional e Técnica (Meta 11),à formação de professores (Meta 15) ao plano de carreira (Meta 18).

0 Censo Demográfico Brasileiro de 2010, realizado pelo Instituto Brasileiro de Geografia e Estatística (IBGE), apontou que a população brasileira era de 190.755.799 habitantes, dos quais 160.925.791 $(84,4 \%)$ se encontravam no espaço urbano e $29.830 .007(15,6 \%)$ no rural'. Ressalte-se, o próprio IBGE, por meio do documento Classificação e Caracterização dos Espaços Rurais e Urbanos do Brasil: uma aproximação, insere uma nova metodologia para classificar os espaços em urbanos ou rurais. Na nova classificação, o Brasil se torna "menos urbano", tendo registrado que $76 \%$ de sua população se concentra em território predominantemente urbano (IBGE, 2017).

0 Censo Escolar da Educação Básica de 2017, desenvolvido pelo Instituto Nacional de Estudos e Pesquisas Educacionais Anísio Teixeira (INEP), revelou que a localidade urbana concentrava 67,3\% e a rural 32,7\% dos estabelecimentos de ensino da Educação Básica. Em relação às matrículas, existiam 48.608.093alunos matriculados na Educação Básica,

1 Esse contingente de 29.830 .007 pessoas aproxima-se da quantidade populacional da Venezuela (31.304.016) ou do Peru (31.036.656). Fonte: https://www. indexmundi.com/map/? $\mathrm{v}=21 \mathrm{ctr}=\mathrm{sact}=\mathrm{pt}$ dos quais $43.034 .708(88,6 \%)$ se encontravam em escolas urbanas e $5.573 .385(11,4 \%)$ em unidades rurais. 0 total de docentes em atuação contabilizou 2.192.224 profissionais, sendo $345.604(15,8 \%)$ no espaço rural e $1.909 .462(87,1 \%)$ no urbano. Nesse ano também foram registradas 2.169.220 turmas, sendo 1.842 .905 (85,0\%) localizadas em áreas urbanas e $326.315(15,0 \%)$ em áreas rurais.

Embora existam dados censitários sobre a Educação Básica desenvolvida no país, poucos trabaIhos se debruçaram à análise da oferta específica no contexto rural. Portanto, é necessário compreender a configuração da Educação Básica no meio rural, levando-se em conta que o Brasil possui vasta extensão territorial, registra diferenças regionais, econômicas e culturais e é marcado por uma grande desigualdade social.

Este estudo encontra-se estruturado em três seções, além das considerações finais. A primeira seção realiza um levantamento dos estudos sobre a Educação Básica ofertada em áreas rurais. A segunda descreve a fonte de dados, ou seja, explicita o censo utilizado para analisar a Educação Básica desenvolvida no Brasil tanto no meio urbano quanto no rural. A terceira seção exibe os resultados da análise comparativa entre a oferta da Educação Básica nas áreas urbanas e nas rurais. Encerra-se com as considerações finais.

\section{A Educação Básica no espaço rural brasileiro}

O Censo Demográfico de 2010 -o último realizado pelo IBGE- mostrou a manutenção do processo de urbanização da população brasileira, embora a tendência tenha desacelerado nos últimos anos. A proporção de pessoas residentes na zona rural, era de 32\%, em 1980, e diminuiu para 15\%, em 2014 (Figura 1). Em aproximadamente cinco décadas, a população rural reduziu pela metade.

Em 2014, a população em localidades rurais do país contabilizava aproximadamente 29,8 milhões de pessoas (15,6\%). Esse contingente demonstraos desafios para a garantia de educação de qualidade, respeitadora das diversidades do espaço rural.

Um dos problemas da educação no espaço rural é a exclusão escolar. 0 documento Cenário $d a$ 


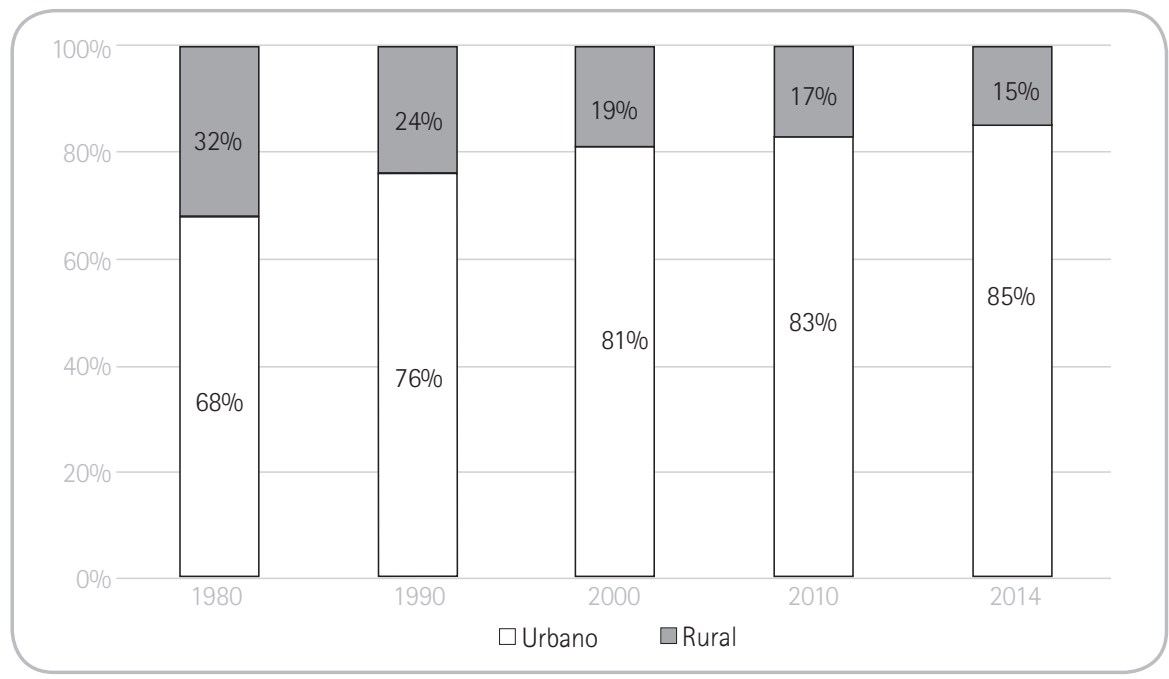

Figura 1 Distribuição da população residente de acordo com a localização do domicílio - Brasil - 1980/1990/2000/2010/2014

Fonte: Censo Demográfico 2010 e PNAD 2014.

exclusão escolar no Brasil, organizado pelo Fundo das Nações Unidas para a Infância (Unicef), apontou que 8,3\% (661.110) da população rural com idade entre 4 e 17 anos se encontravam fora da escola. Segundo o documento:

[d]ispersos pelo Brasil, 661.110 meninos e meninas estão longe das salas de aula fora das cidades, vilas e áreas urbanas isoladas, seja por falta de vagas em escolas próximas, problemas no transporte escolar ou outros fatores que impedem o acesso e a permanência escolar. Muitas dessas crianças e desses adolescentes vivem na Região Amazônica e no Semiárido brasileiro, espalhados por mais de 2 mil municipios. (Unicef, 2017, p. 5).

0 relatório Panorama da Educação do Campo, desenvolvido pelo INeP, trazdados da Pesquisa Nacional por Amostra de Domicilios (PNAD) de 2004 sobre a educação ofertada nas áreas rurais. A escolaridade média da população de 15 anos ou mais residentes em áreas rurais era de 4 anos de estudo, o que corresponde quase à metade do valor médio estimado para a população urbana, equivalente a 7,3 anos (INEP, 2007). Sobre a diferença rural-urbana, o relatório destacou que:

[s]e considerarmos que o aumento de um ano de estudo para o conjunto da população leva em torno de uma década, mantido o padrão histórico, a população rural levaria mais de 30 anos para atingir o atual nivel de escolaridade da população urbana. Isso dá uma mediada brutal disparidade existente entre as populações urbana e rural em termos de escolaridade. (INEP, 2007, pp. 15-16).

Outro indicador da fragilidade educacional no Brasil, sobretudo no meio rural, foi a taxa de analfabetismo. Em 2015, conforme os dados da PNAD, 19,8\% da população adulta (15 anos ou mais) residente no espaço rural era analfabeta ${ }^{2}$ e 5,9\% na zona urbana.

A superação das desigualdades educacionais, nesse caso, voltado à população do campo, deve apoiar-se nos princípios estabelecidos nas diversas iniciativas institucionais (Brasil, 1988; Brasil, 1996; Brasil, 2014a). Deve contar com o envolvimento de movimentos como a Escola Ativa, as Escolas Famílias Agrícolas e Casas Familiares Rurais (Ceffas), o Movimento dos Trabalhadores Sem Terra (MST), o Movimento de Educação de Base (MEB) e a Confederação Nacional dos Trabalhadores na Agricultura (Contag) ${ }^{3}$.

2 Essa taxa de analfabetismo não inclui os analfabetos funcionais, ou seja, a população com menos que as quatro séries do Ensino Fundamental.

30 programa Escola Ativa visa melhorar a qualidade do desempenho escolar em classes multisseriadas das escolas do campo. Entre as principais estratégias estão: implantar nas escolas recursos pedagógicos que estimulem a construção do conhecimento do aluno e capacitar professores.

As Escolas Famílias Agrícolas e Casas Familiares Rurais (CEFFAs) utilizam a pedagogia da alternância adequando-se às caracteristicas da vida rural, 
A LDBEN, em seu Art. 28, aponta que, para ofertara Educação Básica para a população rural, os sistemas de ensino devem promover as adaptações necessárias à sua adequação, às peculiaridades da vida rural e de cada região, conforme estabelecido:

1- conteúdos curriculares e metodologias apropriadas às reais necessidades e interesses dos alunos da zona rural; II- organização escolar própria, incluindo adequação do calendário escolar às fases do ciclo agrícola e às condições climáticas; III - adequação à natureza do trabalho na zona rural. (Brasil, 1996, p. 25).

Ademais a Lei № 12.960/2014 trouxe critérios mais rigorosos para o fechamento de escolas do campo, indígenas e quilombolas. 0 fechamento deve ser precedido de manifestação do órgão normativo do respectivo sistema de ensino, que necessita considerar a justificativa apresentada pela Secretaria de Educação, a análise do diagnóstico do impacto da ação e a manifestação da comunidade escolar (Brasil, 2014b).

0 documento Panorama da Educação do Campo (INEP, 2007) sintetizouas principais questões que afetam a educação do campo: a insuficiência e a precariedade das instalações físicas da maioria das escolas; as dificuldades de acesso dos professores e alunos às escolas; a falta de professores concursados e com formação mínima adequada; a utilização de currículo escolar que privilegia uma visão urbana de educação e desenvolvimento; a ausência de assistência pedagógica e supervisão escolar nas escolas rurais; o predomínio de classes multisseriadas com educação de baixa qualidade; a falta de atualização das propostas

procurando, além de fixar o homem no campo, servir como instrumento do desenvolvimento agrícola.

A Escola da Itinerante, criada no âmbito do Movimento Sem Terra visa garantir o direito à educação das crianças, adolescentes, jovens e adultos em situação de itinerância, enquanto estão acampados, lutando pela desapropriação das terras improdutivas e implantação do assentamento.

0 Movimento de Educação de Base (MEB) é um organismo vinculado a Conferência Nacional dos Bispos do Brasil - CNBB, foi fundado em 21 de março de 1961.Visa contribuir para promoção humana integral e superação da desigualdade social por meio de programas de educação popular libertadora ao longo da vida.

A Confederação Nacional dos Trabalhadores na Agricultura (Contag) compõe o Movimento Sindical de Trabalhadores e Trabalhadoras Rurais (MSTR), que luta pelos direitos de mais de 15,7 milhões (PNAD/IBGE, 2009) de homens e mulheres do campo e da floresta, que são agricultores(as) familiares, acampados(as) e assentados(as) da reforma agrária, assalariados(as) rurais, meeiros, comodatários, extrativistas, quilombolas, pescadores artesanais e ribeirinhos. Esse movimento social contribuiu e contribui no avanço de ordenamentos legais e programas e projetos para a educação do campo. pedagógicas das escolas rurais; o baixo desempenho escolar dos alunos e elevadas taxas de distorção idade-série; os baixos salários e sobrecarga de trabalho dos professores; a necessidade de reavaliação das políticas de nucleação das escolas; a implementação de calendário escolar adequado às necessidades do meio rural (INEP, 2007).

Souza e Sousa (2015) analisaram aspectos relacionados às condições de trabalho docente de professoras de classes multisseriadas do meio rural do Território do Baixo Sul baiano. Os resultados da pesquisa evidenciaram a precarização nas condições de trabalho docente no contexto da multisseriação e apontaram estratégias de superação para as professoras realizarem o trabalho docente, face às adversidades vividas no cotidiano profissional e escolar.

Furtado (2004) apontou o cenário de precariedade vivenciados pelos docentes atuantes no espaço rural brasileiro:

Além da baixa qualificação e salários inferiores, eles enfrentam a sobrecarga de trabalho, alta rotatividade e dificuldades de acesso à escola, em função da inexistência ou precariedade das estradas, falta de transporte e falta de ajuda de custo para a sua locomoção. Alguns deslocam-se de bicicleta, outros à pé do seu local de moradia, percorrendo quilômetros de distância, no sol causticante do Nordeste. (Furtado, 2004, p. 64).

Em pesquisa realizada em uma escola rural do interior do Rio de Janeiro, Neves (2007) enfatizou a situação de precariedade encontrada. Conforme 0 depoimento de um professor entrevistado, os aspectos mais negativos da escola relacionavam-se:

[...] à falta de espaço físico construído, pois não há sala de professores, quadra de esportes coberta, banheiros em número suficiente e, pior, refeitório, o que faz com que se comam as refeições sentados no chão ou em pé, com o prato quente à mão. Além disso, a biblioteca, a cozinha, a secretaria e muitas salas de aula são espaços exíguos e insuficientes para a realização do trabalho escolar. (Neves, 2007, p. 8).

Canário (1996), em estudos sobre as escolas rurais de Portugal, sinalizou que as questões capazes de afetar a escola no espaço rural não se constituiam somente de problemáticas internas ao sistema de 
ensino escolar. Elas eram mais amplas e se relacionavam à própria constituição da sociedade, em particular a brasileira, o que nos leva a pensar a escola em contexto técnico epolítico.

Portanto, pensar a educação escolar oferecida em escolas rurais, as principais questões, os desafios e as potencialidades é também refletir sobre o processo de desenvolvimento da sociedade brasileira com suas contradições. Martins (1994) apontou que a formação, a manutenção e a dominação da propriedade privada da terra no Brasil, marcado por sua estrutura fundiária altamente concentrada, sempre esteve ligada a sujeitos e classes sociais dominantes, tendo esse movimento sido denominado pelo autor de "poder do atraso".

\section{Fonte de dados}

Os microdados utilizados foram provenientes do Censo Escolar da Educação Básica, desenvolvido anualmente pelo INEP. Os principais objetivos desse levantamento são oferecer informações estatísticas para a realização de diagnósticos e análises sobre a realidade do sistema educacional e subsidiar a definição e a implementação de políticas públicas da área. Essas informações servem para referenciar a transferência de recursos públicos, como ocorre com a merenda e o transporte escolar, a distribuição de livros e de uniformes, a implantação de bibliotecas, a instalação de energia elétrica, o dinheiro direto na escola e o fundo de manutenção e desenvolvimento da educação básica e de valorização dos profissionais da educação (Fundeb).

Como possui caráter censitário, abrange todas as unidades educacionais do país localizadas em áreas urbanas e rurais. Contempla todas as etapas da Educação Básica (Educação Infantil, Ensino Fundamental e Ensino Médio) das diferentes modalidades (ensino regular, educação especial, educação de jovens e adultos e educação profissional de nível técnico), tanto das redes públicas (federal, estaduais e municipais) quanto das instituições privadas (particular, comunitária, confessional e filantrópica).

Os dados das escolas são informados pelo diretor ou responsável por meio de um sistema online de coleta de dados formado por quatro tipos de cadastros: 1) escolas; 2) turmas; 3) alunos; e 4) profissionais escolares em sala de aula. Este estudo utiliza dados referentes a 2017, período em que foram registradas 282.362 unidades educacionais, 2.169.220 turmas, 2.192.224 profissionais e 48.608 .093 matrículas.

\section{Resultados}

Esta seção apresenta os resultados da comparação entre os aspectos infraestruturais existentes nas unidades de Educação Básica localizadas em áreas urbanas e em rurais. Foram analisados dados das escolas sobre: a situação de funcionamento; a dependência administrativa; a etapa de atendimento; o local de funcionamento; a existência de espaços internos; a existência de espaços externos; a existência de recursos materiais; e a existência de serviços básicos de infraestrutura.

A primeira característica analisada refere-se à situação de funcionamento das escolas, ou seja, verifica se elas se encontravam ou não em atividade. Entre os estabelecimentos de localização urbana, 78,8\% estavam em atividade, contra 49,2\% nas unidades rurais (Tabela 1). Tal cenário revela a configuração de oferta da Educação Básica no Brasil, cuja

Tabela 1 Distribuição das unidades de Educação Básica de acordo com a situação de funcionamento- Brasil, 2017

\begin{tabular}{lrrrr}
\multicolumn{1}{c}{ Situação de funcionamento } & \multicolumn{2}{c}{ Urbana } & \multicolumn{2}{c}{ Rural } \\
Em atividade & Freq. & \% & Freq. & \% \\
\hline Paralisada & 125.155 & 78,8 & 60.770 & 49,2 \\
\hline Extinta (ano do Censo) & 15.458 & 9,7 & 31.425 & 25,5 \\
\hline Extinta anos anteriores & 1.532 & 1,0 & 2.141 & 1,7 \\
\hline Total & 16.778 & 10,6 & 29.103 & 23,6 \\
\hline
\end{tabular}

Fonte: Elaboração dos autores, com base nos microdados do Censo Escolar 2017. 
participação das unidades localizadas em áreas rurais decresce em ritmo superior aos estabelecimentos urbanos. Embora exista maior número de escolas urbanas, devido ao fato de ser nessa localização onde vive a maior parte da população do país, a parcela de unidades que foram extintas ou tiveram seu funcionamento paralisado foi bem maior nos estabelecimentos rurais $(50,8 \%)$.

A ausência do processo educativo em consequência do fechamento de escolas interfere em três elementos básicos. 0 primeiro relaciona-se à negação das diretrizes, dos princípios e das metas estabelecidas nos dispositivos legais ${ }^{4}$ regulatórios da educação brasileira. A legislação relacionada ao campo educacional assegura o estabelecimento de políticas públicas voltadas à ampliação e à adequação às especificidades das populações do campo. 0 segundo elemento incide diretamente na vida das famílias, das crianças e dos jovens das áreas rurais, pois devido à ausência de escolas, eles necessitam ajustar as suas condições de vida. Diante desse ajuste, muitas vezes chegam a abandonar os assentamentos e os locais onde vivem para conseguirem garantir o direito à educação das crianças e jovens. 0 terceiro elemento relaciona-se diretamente à vida das crianças e dos jovens da zona rural, pois devido à ausência de escolas próximas de onde moram precisam se deslocar por horas (muitas vezes mais tempo do que passam em sala de aula) em estradas e transportes precários.
Isso sem contar a inadequação da alimentação e a inviabilidade de possuir tempo para o descanso e para as atividades de lazer.

Ao associar as informações sobre a localização e a dependência administrativa das escolas, observa-se maior participação dos municípios na oferta da Educação Básica nas áreas rurais (89,9\%) em oposição às urbanas $(47,2 \%)$ (Tabela 2). Embora a população urbana seja bem superior à rural, em números absolutos, a quantidade de escolas rurais (54.611) se aproxima da de urbanas (59.031). Tanto nas áreas urbanas quanto nas rurais a rede federal apresenta pouca cobertura. Especificamente nas unidades privadas, enquanto a sua participação engloba quase um terço $(32,0 \%)$ das escolas urbanas, é muito restrita no meio rural (1,1\%).

A superioridade de escolas rurais custeadas pelos entes federados municipais recai no regime de colaboração entre as esferas públicas e os respectivos sistemas de ensino, conforme expresso na LDBEN (Art. 241). Nesse regime, a atuação prioritária dos municípios deve ser a Educação Infantil e o Ensino Fundamental $\left(\S 2^{\circ}\right)$ e a dos estados e do Distrito Federal, o Ensino Fundamental e o Ensino Médio (§ $3^{\circ}$ ). Ressalte-se, as duas primeiras etapas da Educação Básica - Educação Infantil e Ensino Fundamental - possuem as maiores quantidades de matrículas.

Apesar do crescimento da participação privada na oferta da Educação Básica - foco de grandes grupos privados educacionais-, ela ocorre primordialmente no

Tabela 2 Distribuição das unidades de Educação Básica em atividade de acordo com a localização ea dependência administrativa - Brasil, 2017

\begin{tabular}{|c|c|c|c|c|c|c|}
\hline \multirow{2}{*}{ Dependência administrativa } & \multicolumn{2}{|c|}{ Urbana } & \multicolumn{2}{|c|}{ Rural } & \multicolumn{2}{|c|}{ Total } \\
\hline & Freq. & $\%$ & Freq. & $\%$ & Freq. & $\%$ \\
\hline Federal & 608 & 0,5 & 92 & 0,2 & 700 & 0,4 \\
\hline Estadual & 25.438 & 20,3 & 5.410 & 8,9 & 30.848 & 16,6 \\
\hline Municipal & 59.031 & 47,2 & 54.611 & 89,9 & 113.642 & 61,1 \\
\hline Privada & 40.078 & 32,0 & 657 & 1,1 & 40.735 & 21,9 \\
\hline Total & 125.155 & 100 & 60.770 & 100 & 185.925 & 100 \\
\hline
\end{tabular}

Fonte: Elaboração dos autores, com base nos microdados do Censo Escolar 2017.

\footnotetext{
4 Apesar de reconhecer que houve a sanção de lei que dificultava o fechamento de escolas rurais, indígenas e quilombolas, trata-se da Lei №12.960/2014, de 27 de março de 2014, que altera LDB para fazer constar exigência de manifestação de órgão normativo - como os Conselhos Municipais de Educação - do sistema de ensino para o fechamento desse tipo de escola. Além disso, exige que o órgão normativo opine sobre o fechamento da unidade de ensino nessas áreas, e que a comunidade escolar seja ouvida e a Secretaria de Educação do estado justifique a necessidade de encerramento das atividades da escola. (Brasil, 2014b).
} 
espaço urbano. Nas áreas rurais, a parcela de escolas privadas atinge somente 1,1\% dos estabelecimentos.

A oferta da Educação Básica ocorre de forma distinta entre etapas de atendimento. Do total de escolas ofertantes dos anos iniciais do Ensino Fundamental,46,8\% refere-se a escolas rurais e 53,2\% a escolas urbanas (Tabela 3). Situação mais desequilibrada ocorre em relação ao Ensino Médio, pois somente cerca de uma a cada dez escolas dessa etapa se encontra em localidades rurais. Isso é, caso o aluno queira cursar o
Ensino Médio, ele se vê forçado a deixar a zona rural para ir à cidade para realizar os estudos.

Sobre as condições da oferta, o local de funcionamento das escolas permite avaliar o nivel de adequação desses espaços. Nas localidades rurais, em oposição às urbanas, existe parcela bem superior de escolas cujo funcionamento ocorre em locais readaptados para o propósito educacional, como é o caso de galpões/ranchos/barracões (Tabela 4). Nas zonas rurais, percentual superior também foi registrado em

Tabela 3 Distribuição das unidades de Educação Básica em atividade de acordo com a localização e a subetapa de atendimento ${ }^{5}$ - Brasil, 2017

\begin{tabular}{lcccccc}
\multicolumn{1}{c}{ Subetapa da Educação Básica } & \multicolumn{2}{c}{ Total } & \multicolumn{2}{c}{ Urbana } & \multicolumn{2}{c}{ Rural } \\
& Freq. & $\%$ & Freq. & $\%$ & Freq. & $\%$ \\
\hline Creche & 67.204 & 100,0 & 50.437 & 75,1 & 16.767 & 24,9 \\
\hline Pré-escola & 104.351 & 100,0 & 60.640 & 58,1 & 43.711 & 41,9 \\
\hline Ensino Fundamental - anos iniciais & 113.464 & 100,0 & 60.406 & 53,2 & 53.058 & 46,8 \\
\hline Ensino Fundamental - anos finais & 62.181 & 100,0 & 43.518 & 70,0 & 18.663 & 30,0 \\
\hline Ensino Médio & 27.273 & 100,0 & 24.576 & 90,1 & 2.697 & 9,9 \\
\hline
\end{tabular}

Fonte: Elaboração dos autores, com base nos microdados do Censo Escolar 2017.

Tabela 4 Distribuição das unidades de Educação Básica em atividade de acordo com o local de funcionamento e a localização - Brasil, 2017

\begin{tabular}{lrrrr} 
& \multicolumn{2}{c}{ Urbana } & \multicolumn{2}{c}{ Rural } \\
& \multicolumn{1}{c}{ Freq. } & \multicolumn{1}{c}{$\%$} & \multicolumn{1}{c}{ Freq. } & \multicolumn{1}{c}{$\%$} \\
Tipo de edificação & & & & \\
Prédio escolar & 121.551 & 97,1 & 56.637 & 93,2 \\
\hline Templo/Igreja & 648 & 0,5 & 409 & 0,7 \\
\hline Casa do professor & 237 & 0,2 & 649 & 1,1 \\
\hline Galpão/Paio/Rancho/Barracão & 296 & 0,2 & 2.979 & 4,9 \\
\hline Outros & 2.423 & 2,0 & 96 & 0,1 \\
\hline Total & 122.732 & 100,0 & 60.674 & 100,0 \\
\hline Tipo de ocupação & & & & \\
Prédio escolar próprio & 99.003 & 81,4 & 53.411 & 94,3 \\
\hline Prédio escolar alugado & 15.677 & 12,9 & 742 & 1,3 \\
\hline Prédio escolar cedido & 6.871 & 5,7 & 2.474 & 4,4 \\
\hline Total & 121.551 & 100,0 & 56.637 & 100,0 \\
\hline Local de funcionamento diferenciado & & & & \\
Sim & 447 & 0,4 & 10.336 & 17,0 \\
\hline Não & 124.708 & 96,6 & 50.434 & 83,0 \\
\hline Total & 125.155 & 100,0 & 60.770 & 100,0 \\
\hline
\end{tabular}

Fonte: Elaboração dos autores, com base nos microdados do Censo Escolar 2017.

5 A mesma escola de Educação Básica pode oferecer, concomitantemente, mais de uma etapa de ensino.
6 Essa categoria contempla:salas de empresa; unidade de atendimento socioeducativo; unidade prisional; salas em outras escolas; prédio compartilhado; outros. 

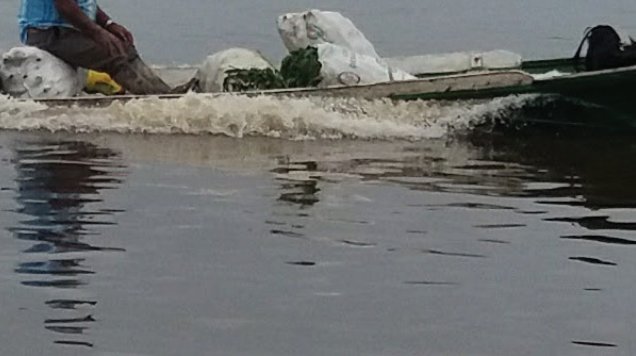
relação às escolas com funcionamento na própria casa dos professores.

Outra informação analisada refere-se ao tipo de ocupação, sendo registrado maior percentual de prédios próprios na zona rural $(94,3 \%)$ do que na zona urbana $(81,4 \%)$ (Tabela 4). Os prédios escolares cedidos contabilizaram 5,7\% na zona urbana e 4,4\% na zona rural. Já os prédios alugados, abrangeram $12,9 \%$ daqueles de localidade urbana e 1,3\% da rural.

Nas localidades rurais se encontram a maior parte dos grupos étnico-raciais, como é o caso das áreas de assentamento, das terras indígenas, das áreas remanescentes de quilombos e das unidades de uso sustentável. No pais, 17,0\% das escolas rurais correspondiam a locais de funcionamento diferenciados, contra somente 0,4\% das urbanas (Tabela 4).

Os dados do Censo Escolar mostraram ainda o tipo de localização diferenciada das escolas: 4.414 (7,3\%) encontravam-se em áreas de assentamento; 3.168 $(5,2 \%)$ em terras indígenas; $2.242(3,7 \%)$ em áreas remanescente de quilombos; e $454(0,7 \%)$ em unidades de uso sustentável.

A precariedade das unidades educacionais rurais é maior que a urbanas em relação à existência de diferentes espaços internos (Tabela 5). Em relação aos ambientes administrativos, $86,1 \%$ das escolas urbanas possuiam sala de diretoria, 74,4\% tinham sala de professores e $80,3 \%$ possuiam secretaria. Nas escolas rurais, esses valores equivaleram a 34,2\%, 24,7\% e 33,1\%, respectivamente. Existiam bibliotecas e/ou salas de leitura em $64,9 \%$ das escolas urbanas contra somente $21,5 \%$ das escolas rurais. E os auditórios, em $14,3 \%$ de escolas urbanas e 2,2\% de escolas rurais.

Nos espaços necessários ao fornecimento de merenda aos estudantes, os refeitórios existiam em $55,4 \%$ das escolas urbanas, em contraposição a 17,6\% das escolas rurais (Tabela 5). A despensa fazia parte de $62,5 \%$ das escolas urbanas e de $41 \%$ das escolas rurais. A cozinha foi a única estrutura com baixa diferença entre as escolas urbanas $(91,7 \%)$ e as rurais $(90,7 \%)$.

A existência de laboratório de ciências e de laboratório de informática foi verificada em 1,6\% e 20,4\% das escolas rurais, respectivamente (Tabela 5). Entre as escolas urbanas, essas taxas subiram para 15,0\% e 49,3\%. Embora não faça a segmentação de acordo com a etapa da Educação Básica, 18,2\% das escolas urbanas e somente 1,3\% das rurais possuiam berçário.

Tabela 5 Distribuição das unidades de Educação Básica em atividade de acordo com a existência de espaços internos e a localização - Brasil, 2017

\begin{tabular}{|c|c|c|c|c|}
\hline \multirow{2}{*}{ Espaços internos das escolas em atividade } & \multicolumn{2}{|c|}{ Urbana } & \multicolumn{2}{|c|}{ Rural } \\
\hline & Freq. & $\%$ & Freq. & $\%$ \\
\hline Sala de diretoria & 107.727 & 86,1 & 20.782 & 34,2 \\
\hline Sala de professores & 93.161 & 74,4 & 15.028 & 24,7 \\
\hline Secretaria & 100.505 & 80,3 & 20.131 & 33,1 \\
\hline Auditório & 17.851 & 14,3 & 1.361 & 2,2 \\
\hline Laboratório de informática & 61.723 & 49,3 & 12.370 & 20,4 \\
\hline Laboratório de ciências & 18.766 & 15,0 & 945 & 1,6 \\
\hline Biblioteca e/ou Sala de leitura & 81.193 & 64,9 & 13.048 & 21,5 \\
\hline Berçário & 22.732 & 18,2 & 807 & 1,3 \\
\hline Banheiro dentro do prédio & 109.860 & 87,8 & 44.246 & 72,8 \\
\hline $\begin{array}{l}\text { Dependências e vias adequadas a alunos com deficiência } \\
\text { ou mobilidade reduzida }\end{array}$ & 49.005 & 39,2 & 5.928 & 9,8 \\
\hline $\begin{array}{l}\text { Sala de recursos multifuncional para Atendimento } \\
\text { Educacional Especializado (AEE) }\end{array}$ & 29.862 & 23,9 & 4.801 & 7,9 \\
\hline Cozinha & 114.726 & 91,7 & 55.089 & 90,7 \\
\hline Refeitório & 69.279 & 55,4 & 10.673 & 17,6 \\
\hline Almoxarifado & 68.272 & 54,5 & 9.806 & 16,1 \\
\hline Despensa & 78.165 & 62,5 & 24.942 & 41,0 \\
\hline
\end{tabular}

Fonte: Elaboração dos autores, com base nos microdados do Censo Escolar 2017. 
Ao focar a atenção nos alunos com deficiências ou mobilidade reduzida, 9,8\% das escolas rurais possuiam dependências e vias adequadas a esse público e 7,9\% tinham sala de recursos multifuncionais para Atendimento Educacional Especializado (AEE). Nas escolas urbanas, essas instalações foram encontradas em 39,2\% e 23,9\% das unidades de Educação Básica, respectivamente.

Outro conjunto de aspectos das escolas refere-se aos espaços externos. Os resultados demonstraram a precariedade mais acentuada das escolas rurais em relação às urbanas (Tabela 6). A única exceção - cujo percentual de existência nas escolas rurais foi maior que o das urbanas - se refere ao banheiro fora da escola, existente em $21,1 \%$ das escolas rurais e $15,7 \%$ das urbanas. Nem mesmo as áreas verdes, caracteristica típica das zonas rurais, foram mais encontradas nas áreas rurais.

Os espaços externos mais presentes nas escolas de ambas as localidades foram os pátios cobertos e os pátios descobertos (Tabela 6). Nas escolas urbanas, os pátios foram encontrados em mais da metade dos estabelecimentos e nas escolas rurais, em aproximadamente um a cada quatro unidades de Educação Básica.

Uma parcela de 45,1\% das escolas urbanas e $12,9 \%$ das escolas rurais possuiam quadra de esportes (Tabela 1). Em relação ao parque infantil, existia em $43,6 \%$ das escolas urbanas e $8,1 \%$ das rurais.

A oferta de serviços básicos de infraestrutura (água, energia elétrica, esgoto e coleta de lixo) foi mais escassa nas escolas rurais brasileiras, em comparação às urbanas (Tabela 7). Inclusive, serviços quase universalizados nas escolas urbanas, como é o caso da energia elétrica proveniente da rede pública e da coleta periódica de lixo, ainda não eram disponibilizados para $13,3 \%$ e $67,2 \%$ das escolas rurais, respectivamente.

0 fornecimento de água pela rede pública ocorreu para mais de $90 \%$ das escolas do meio urbano (Tabela 7). Nas escolas rurais, essa proporção atingiu $30,3 \%$. As outras possiblidades das escolas terem acesso à água, conforme os microdados do Censo Escolar, foram poços $(28,8 \%)$, cacimbas $(23,2 \%)$, rios $(13,7 \%)$. Ainda, 9,2\% (5.597) das escolas rurais não possuiam água.

Tipo de serviço básico de infraestrutura pouco encontrado nas escolas rurais foi o de esgote ela rede pública, tendo sido encontrado em somente $5,5 \%$ das unidades. Nas escolas urbanas esse valor atingiu 71,3\%.

Outro serviço - atualmente considerado básico - é a internet, sendo cada vez mais demandado pelas escolas, inclusive, para o preenchimento do Censo Escolar. Nas localidades urbanas, 85\% das escolas a possuiam, contra menos de um terço $(31,9 \%)$ das rurais.

A disponibilização de recursos materiais (apareIho de TV, videocassete, DVD, antena parabólica, copiadora, retroprojetor, impressora, aparelho de som, computador, data show, máquina fotográfica e filmadora) nas escolas urbanas do pais é menor do que nas rurais (Tabela 8). No contexto escolar, tais equipamentos são necessários tanto para o funcionamento administrativo e a gestão do estabelecimento quanto para o planejamento e o desenvolvimento das atividades docentes.

Os computador esse encontravam disponíveis em 91,5\% das escolas urbanas e pouco mais da metade $(51,9 \%)$ das escolas rurais (Tabela 8$)$. Inclusive, esse tipo

Tabela 6 Distribuição das unidades de Educação Básica em atividade de acordo com a existência de espaços externos e a localização - Brasil, 2017

\begin{tabular}{lrrrr}
\multicolumn{1}{c}{ Espaços externos das escolas em atividade } & \multicolumn{2}{c}{ Urbana } & \multicolumn{2}{c}{ Rural } \\
Quadra de esportes & Freq. & \% & Freq. & \% \\
\hline Parque infantil & 56.506 & 45,1 & 7.839 & 12,9 \\
\hline Banheiro fora do prédio & 54.585 & 43,6 & 4.923 & 8,1 \\
\hline Pátio coberto & 19.588 & 15,7 & 12.848 & 21,1 \\
\hline Pátio descoberto & 74.523 & 59,5 & 16.176 & 26,6 \\
\hline Área verde & 66.077 & 52,8 & 14.282 & 23,5 \\
\hline Lavanderia & 41.334 & 33,0 & 12.096 & 19,9 \\
\hline
\end{tabular}

Fonte: Elaboração dos autores, com base nos microdados do Censo Escolar 2017. 
de equipamento é necessário para, além das atividades administrativas e pedagógicas a serem desenvolvidas nas escolas, o preenchimento do Censo Escolar.

A disponibilidade de recursos audiovisuais foi bem mais comum nas escolas urbanas (Tabela 8). Dessas, 93,1\% possuiam aparelhos de televisão, 85,6\% aparelhos de DVD e 86,5\% aparelhos de som. Nas escolas rurais, essas taxas foram 58,0\%, 52,7\% e 46,4\%, respectivamente.

Os percentuais de escolas rurais com impressora, copiadora e projetor multimídia contabilizaram, respectivamente, $77,9 \%, 55,9 \%$ e 69,9\% (Tabela 8 ). Nos estabelecimentos rurais, esses valores corresponderam a 40,7\%, 20,2\% e 30,6\% das escolas, respectivamente.

Além de serviços, espaços e recursos materiais, outros dois tipos de suporte à escola foram verificados: o fornecimento de alimentação e a oferta de AEE. Sobre a alimentação, uma parcela de $77,9 \%$ das escolas urbanas a forneciam aos alunos. Nas unidades rurais, essa parcela atingiu a quase totalidade das escolas (99,3\%). Trata-se de uma necessidade dos alunos dessas escolas, pois, geralmente, os estabelecimentos educacionais ficam longe das residências, cujo trajeto pode demandar longas caminhadas ou viagens cansativas de ônibus ou, inclusive, de barco. Sobre o AEE, até mesmo nas escolas urbanas foi escassa a oferta desse tipo de serviço $(20,6 \%)$. Nas escolas rurais, ainda mais baixo $(6,4 \%)$.

\section{Considerações finais}

Ao comparar dados censitários sobre a Educação Básica ofertada no Brasil, tornou-se realçada a diferença estrutural abissal existente entre as escolas urbanas e as rurais. Na busca pela valorização dos profissionais da educação, por meio da oferta de melhores condições de trabalho, encontra-se um panorama preocupante, marcado pela precariedade dos aspectos de

Tabela 7 Distribuição das unidades de Educação Básica em atividade de acordo com a existência de serviços básicos de infraestrutura e a localização - Brasil, 2017

\begin{tabular}{lrrrr}
\multicolumn{1}{c}{ Serviços básicos de infraestrutura } & \multicolumn{2}{c}{ Urbana } & \multicolumn{2}{c}{ Rural } \\
\hline Água filtrada & Freq. & \% & Freq. & \% \\
\hline Água rede pública & 114.558 & 91,5 & 46.581 & 76,7 \\
\hline Energia elétrica da rede pública & 117.866 & 94,2 & 18.396 & 30,3 \\
\hline Esgoto da rede pública & 124.932 & 99,8 & 52.717 & 86,7 \\
\hline Coleta periódica de lixo & 89.223 & 71,3 & 3.323 & 5,5 \\
\hline Internet & 124.140 & 99,1 & 19.947 & 32,8 \\
\hline
\end{tabular}

Fonte: Elaboração dos autores, com base nos microdados do Censo Escolar 2017.

Tabela 8 Distribuição das unidades de Educação Básica escolas em atividade de acordo com a existência derecursos materiais e a localização - Brasil, 2017

\begin{tabular}{lrrrr}
\multicolumn{1}{c}{ Recursos materiais } & \multicolumn{2}{c}{ Urbana } & \multicolumn{2}{c}{ Rural } \\
Aparelho de televisão & Freq. & \% & \multicolumn{1}{c}{ Freq. } & \multicolumn{1}{c}{$\%$} \\
\hline Videocassete & 116.574 & 93,1 & 35.264 & 58,0 \\
\hline DVD & 24.799 & 19,8 & 4.246 & 7,0 \\
\hline Antena parabólica & 107.090 & 85,6 & 31.999 & 52,7 \\
\hline Copiadora & 29.862 & 23,9 & 10.370 & 17,1 \\
\hline Impressora & 69.950 & 55,9 & 12.252 & 20,2 \\
\hline Aparelho de som & 97.532 & 77,9 & 24.712 & 40,7 \\
\hline Computador & 108.199 & 86,5 & 28.170 & 46,4 \\
\hline Projetor multimídia (Datashow) & 114.472 & 91,5 & 31.539 & 51,9 \\
\hline Máquina fotográfica/Filmadora & 87.448 & 69,9 & 18.608 & 30,6 \\
\hline
\end{tabular}

Fonte: Elaboração dos autores, com base nos microdados do Censo Escolar 2017. 
infraestrutura das escolas. Tais fatores dificultam a melhoria da oferta da educação com qualidade.

É comum encontrar escolas nas localidades rurais sem salas de direção e de professores, secretaria, laboratórios, bibliotecas, refeitórios, banheiros, cozinha. Tais estruturas são fundamentais para compor ambiente adequado ao trabalho docente e à aprendizagem dos alunos. 0 cenário se mostra ainda mais preocupante ao avaliar espaços como quadra de esportes, parques, pátios e áreas verdes, necessários à realização de práticas educativas diversas.

Embora não tenha sido analisada, alguns fatores podem indicar que a realidade das escolas rurais se torna ainda mais precária à medida em que se afasta dos grandes centros urbanos. É necessário, de antemão, identificar medidas que levem em conta a distância ou a densidade populacional dos municípios do país.

\section{Referências}

Brasil. Constituição. (1988). Constituição Federal da República Federativa do Brasil. Brasilia, DF: Senado Federal.

Brasil. (1996). Lei № 9.394, de 20 de dezembro de 1996. Diário Oficial [da] República Federativa do Brasil, Poder Legislativo, Brasília, DF, 23 dez. 1996. Seção 1, n. 248, p. 27833-27841.

Brasil. (2014a). Lei № 13.005, de 25 de junho de 2014. Diário Oficial [da] República Federativa do Brasil, Poder Legislativo, Brasília, DF, 26 jun. 2014. Seção 1, n. 120-A, edição extra, p. 1-7.

Brasil. (2014b). Lei № 12.960, de 27 de março de 2014. Diário Oficial [da] República Federativa do Brasil, Poder Legislativo, Brasilia, DF, 27 mar. 2014.
Canário, R. (1996). Os estudos sobre a escola: problemas e perspectivas. In: Barroso, J. (Org.). O estudo da escola (pp. 125-150). Porto: Porto Editora.

Fundo das Nações Unidas para a Infância. Unicef. (2017). Cenário da exclusão escolar no Brasil. Disponivel em: $<$ https://www.unicef.org/brazil/pt/cenario_exclusao_escolar_brasil.pdf>. Acesso em 16 out. 2018.

Furtado, E. D. P. (2004). Estudo sobre a educação para a população rural no Brasil. Disponivel em: <http://www.fao. org/docrep/pdf/009/y5517s/y5517s00.pdf>. Acesso em: 18 de out. 2018.

Instituto Brasileiro de Geografia e Estatística. IBGE. (2017). Classificação e Caracterização dos espaços rurais e urbanos no Brasil: uma aproximação. Rio de Janeiro: IBGE. Disponivel em: https://biblioteca.ibge.gov.br/visualizacao/ livros/liv100643.pdf>. Acesso em 14 de mai. 2018.

Instituto Nacional de Estudos e Pesquisas Educacionais Anísio Teixeira. Inep. (2007). Panorama da educação no campo. Brasilia: IBGE. Disponivel em: <http://portal.inep.gov. br/informacao-da-publicacao/asset_publisher/6JYIsGMAMkW1/document/id/490919>. Acesso em 18 de out. 2018.

Martins, J. S. (1994). O Poder do Atraso: Ensaios de Sociologia da História Lenta. São Paulo: Hucitec.

Neves, E. D. (2007). Trabalho de professores em contexto rural: uma investigação. In: Anais da 30 Reunião da ANPED. Caxambu, MG. Disponivel em: <http://30reuniao.anped.org.br/trabalhos/GT06-3103--Int.pdf>. Acesso em 18 out. 2018.

Souza, E. C.; Sousa, R. C. (2015). Condições de trabalho docente, classes multisseriadas e narrativas de professoras do território do baixo sul baiano: significados e sentidos. Curriculo sem Fronteiras, 15(2), 380-408. 


\section{Diálogo del conocimiento}

El artículo presenta una minuciosa radiografía de la educación rural brasileña en comparación con la oferta urbana, teniendo como principal fuente de análisis, datos censales disponibles en el Instituto Nacional de Estudos e Pesquisas Educacionais Anísio Teixeira (INEP) de Brasil. En el abordaje de la cuestión, se seleccionan y analizan datos con los que es posible observar, desde los primeros párrafos del documento, que la educación rural de ese país es una apuesta en construcción, que lucha por su existencia en un escenario marcado por diversas tensiones, contrariedades y desigualdades.

Si bien es claro que la escuela rural y la urbana poseen desafíos diferentes y que la comparación puede constituirse en ejercicio dificil de materializar, dadas las características de la una y la otra, el escrito permite reconocer cómo las escuelas rurales de Brasil, desde aspectos fundamentales como la infraestructura física, trabajan en condiciones físicas, estructurales y pedagógicas limitadas y signadas por la ausencia de recursos básicos. En ese mismo sentido, el análisis muestra que tienen lugar alli procesos de precarización de la labor docente, de recursos y herramientas pedagógicas, y en general, de la calidad educativa, asociadas a una falta de reconocimiento de la importante tarea que cumple la escuela en los sectores rurales. Una de las conclusiones centrales del estudio es que cuanto más lejos de las urbes se encuentra la escuela, más precarias son sus condiciones.

Se puede afirmar que el articulo muestra un panorama detallado, pertinente y preciso, sobre la comparación que se plantea entre la oferta escolar rural y la oferta urbana en Brasil. De esta forma, se constituye en una invitación a develar las formas en que la desigualdad se legitima, se reproduce y se mantiene en el proceso de garantizar uno de los derechos básicos de toda persona: el acceso a una educación de calidad.

Olga Lucia Reyes Ramírez Universidad Nacional Abierta y a Distancia olgalureyes@yahoo.com 